\title{
The correlation between CYP4F2 variants and chronic obstructive pulmonary disease risk in Hainan Han population
}

Yipeng Ding ${ }^{1,2^{*}+}$, Yixiu Yang ${ }^{1,3+}{ }^{\circ}$ Quanni $\mathrm{Li}^{1,2}$, Qiong Feng ${ }^{3}$, Dongchuan $\mathrm{Xu}^{1,2}, \mathrm{Cibing} \mathrm{Wu}^{3}$, Jie Zhao ${ }^{3}$, Xiaoli Zhou ${ }^{1,2}$, Huan Niu, ${ }^{1,2}$, Ping He ${ }^{1,2}$, Jianfang Liu ${ }^{3}$ and Hongxia Yao ${ }^{1,2^{*}}$

\begin{abstract}
Background: Chronic obstructive pulmonary disease (COPD) is a complex pulmonary disease. Cytochrome P450 family 4 subfamily F member 2 (CYP4F2) belongs to cytochrome P450 superfamily of enzymes responsible for metabolism, its single nucleotide polymorphisms (SNPs) were reported to be involved in metabolism in the development of many diseases. The study aimed to assess the relation between CYP4F2 SNPs and COPD risk in the Hainan Han population.

Method: We genotyped five SNPs in CYP4F2 in 313 cases and 508 controls by Agena MassARRAY assay. The association between CYP4F2 SNPs and COPD risk were assessed by $X^{2}$ test and genetic models. Besides, logistic regression analysis was introduced into the calculation for odds ratio (OR) and $95 \%$ confidence intervals (Cls).

Results: Allele model analysis indicated that rs3093203 A was significantly correlated with an increased risk of COPD. Also, rs3093193 G and rs3093110 G were associated with a reduced COPD risk. In the genetic models, we found that rs3093203 was related to an increased COPD risk, while rs3093193 and rs3093110 were related to a reduced risk of COPD. After gender stratification, rs3093203, rs3093193 and rs3093110 showed the association with COPD risk in males. With smoking stratification, rs3093144 was significantly associated with an increased risk of COPD in smokers. CYP4F2 SNPs were significantly associated with COPD risk.

Conclusions: Our findings illustrated potential associations between CYP4F2 polymorphisms and COPD risk. However, large-scale and well-designed studies are needed to determine conclusively the association between the CYP4F2 SNPs and COPD risk.
\end{abstract}

Keywords: Chronic obstructive pulmonary disease, Susceptibility, Agena MassARRAY technology, Case-control study, CYP4F2, Single nucleotide polymorphism

\section{Background}

Chronic obstructive pulmonary disease (COPD) is a commonly heterogeneous diseases caused by distinct pathophysiological processes, with a high morbidity

\footnotetext{
* Correspondence: dingyipenghainan@163.com; yaohongxia768@163.com ${ }^{\dagger}$ Yipeng Ding and Yixiu Yang are the first authors.

'Department of General Practice, Hainan General Hospital, Haikou 570102, Hainan, China

Full list of author information is available at the end of the article
}

and mortality $[1,2]$. It is defined as an incomplete reversible airflow obstruction with persistent symptoms including dyspnea, cough, and excessive sputum production. As report went, it is the fourth leading cause of death (126, 000 deaths per year) [3], and accounts for $6.4 \%$ of the United States population selfreporting a diagnosis annually [4]. Despite the gradual improvement of people's health awareness and detection technology of COPD, most patients with COPD

C C The Author(s). 2020 Open Access This article is licensed under a Creative Commons Attribution 4.0 International License, which permits use, sharing, adaptation, distribution and reproduction in any medium or format, as long as you give appropriate credit to the original author(s) and the source, provide a link to the Creative Commons licence, and indicate if changes were made. The images or other third party material in this article are included in the article's Creative Commons licence, unless indicated otherwise in a credit line to the material. If material is not included in the article's Creative Commons licence and your intended use is not permitted by statutory regulation or exceeds the permitted use, you will need to obtain permission directly from the copyright holder. To view a copy of this licence, visit http://creativecommons.org/licenses/by/4.0/ The Creative Commons Public Domain Dedication waiver (http://creativecommons.org/publicdomain/zero/1.0/) applies to the data made available in this article, unless otherwise stated in a credit line to the data. 
have never been diagnosed up to 29 million people [5]. In the United States, 75\% of COPD cases are diagnosed as smoking-related, but, other occupational or environmental factors such as diesel exhaust and smoke from indoor cooking contributing to the development of COPD [6]. In China, COPD was considered as the third leading cause of death and accounted for over 0.9 million deaths reported in 2013 [7]. And the latest Chinese national survey of COPD from 2002 to 2004 was conducted among 20, 245 adults. The overall prevalence rate was reported up to $8.2 \%$, thereinto, $12.4 \%$ in men and $5.1 \%$ in women [8], which was likely to associated with cigarette smoking in men [9]. Cigarette smoking is considered as the major environmental risk factor for the development of COPD. But individuals varied greatly in their susceptibility to response to tobacco smoking, illustrating that genetic factors played vital role in the incidence and development of COPD. Recent Genome-wide association studies have provided strong evidence for common susceptibility loci for COPD [10-13].

And Cytochrome P450 family 4 subfamily F member 2 (CYP4F2) encodes a member of the cytochrome P450 superfamily of enzymes involved in many metabolic pathways $[14,15]$. It is responsible for metabolizing arachidonic acid to 20-hydroxyeicosatetraenoic acid (20HETE) and involved in many reactions, such as drug metabolism [16], long-chain fatty acids metabolism [17], and synthesis of cholesterol, steroids and other lipids. Recently, Wang et al. elucidated that the upregulated differentially expressed genes were significantly enriched in the arachidonic acid metabolism pathway, including CYP4F2, PTGDS and PLA2G16 by pathway enrichment analysis and pathway interactive network construction [18]. Again, it's involved in metabolic pathways.

Beyond that, CYP4F2 variants were involved in the development of some diseases.

Polymorphisms of CYP4F2 was reported to be linked with the susceptibility to cardiovascular and cerebrovascular diseases [17]. And variants related-Ischemic stroke (IS) studies indicated that genetic variants in CYP4F2 gene may increase the risk of IS [19-21]. CYP4F2 rs2074900 was recently reported to be related to therapeutic responses to erlotinib in sixty Han Chinese advanced non-small cell lung cancer patients received erlotinib monotherapy [14], illustrating that it may take part in the pathological process of pulmonary disease.

In the present study, we aimed to investigate the association between CYP4F2 SNPs and COPD risk in the Hainan Han population. We hope that our study may provide evidence for the role of CYP4F2 in the pathogenesis of COPD and the prevention and diagnosis of COPD in the future.

\section{Materials and methods}

\section{Ethical statement}

All participants were informed of the research process of the study including the procedures, results, etc., by telephone or by visit. Every participant is randomly recruited and treated fairly, and there is no priority. In this study, we only extracted the participants' blood samples. The other data was obtained during the physical examination and did not cause too much harm to the participants, and we analyzed the related information. At present, they have signed informed consent documents. The protocols were approved by the Institutional Review Boards of the Hainan General Hospital (Med-Eth-Re [2019]42). All procedures performed in studies involving human participants were in compliance with Department of Health and Human Services (DHHS) regulations for human research subject protection.

\section{Study population}

We collected 313 blood samples of patients who had COPD were being diagnosed at the Hainan General Hospital. The case population consisted of 238 men and 75 women, with an average age of $60.05 \pm 6.478$ years. All the COPD patients underwent rigorous examination, including immunohistochemical analysis and pulmonary function examination in line accordance with the criteria of the National Heart, Lung, and Blood Institute and the World Health Organization to form the Global Initiative for Chronic Obstructive Lung Disease (GOLD) [22]. The inclusion criteria: after inhalation of bronchodilator, COPD patients were forced expiratory volume (FEV1)/ forced vital capacity (FVC) $<70 \%$ for the first time indicated that airflow was obstructed and could not be completely reversed. Some other causes of respiratory diseases, such as lung cancer, bronchiectasis, pulmonary fibrosis, pulmonary cystic fibrosis, diffuse bronchiolitis and bronchiolitis obliterans, were excluded.

Totally, the control group of 508 healthy people from the physical examination center of Hainan General Hospital had no history of cancer or other diseases. The control population consisted of 337 men and 171 women, with an average age of $71.80 \pm 10.089$ years. Moreover, the number of non-smokers was more than smokers, and there was no significant difference in the distribution of smoking status in the non-smokers and smokers $(p=0.082)$.

\section{SNP selection and genotyping}

We randomly selected some SNPs in the CYP4F2 gene based on the dbSNP database. Each SNP had a minor allele frequency $(\mathrm{MAF})>5 \%$ listed in the global population of the 1000 Genome Projects (http://www.internationalgenome.org/). And then, we used the Regulome DB (http://www.regulomedb.org/) and HaploReg 
v4.1(https://pubs.broadinstitute.org/mammals/haploreg/ haploreg.php) to predict the function of the selected variants. We extracted genomic DNA from whole blood in accordance with the instructions of the GoldMag whole blood genomic DNA purification kit (GoldMag Co. Ltd., Xi'an, China) and genomic DNA concentration was measured using the NanoDrop 2000 (Thermo Scientific, Waltham, Massachusetts, USA). Agena MassARRAY Assay Design 3.0 software was utilized to design the multiplexed SNP MassEXTEND assay and Agena MasSARRAY RS1000 was used to perform SNP genotyping. Finally, we designed primers for five SNPs (rs3093203, rs3093193, rs12459936, rs3093144 and rs3093110) (Table S1) to genotype in Hainan Han populations. And we performed data sorting and analyses by Agena Bioscience TYPER 4.0 software [23].

\section{Statistical analysis}

Student's t-test and Pearson's chi-square were used to assess differences in age and gender between cases and controls, respectively. And the genotype frequency of the control group was assessed as deviating from the Hardy Weinberg Equilibrium (HWE).

In addition, we used logistic regression analysis provided by the PLINK software (version 1.07) to calculate the association between SNPs and COPD risk. Haploview software (version 4.2) was applied to observe the degree of linkage between these SNPs based on a linkage disequilibrium (LD) map [15]. All $p$-values were twotailed and p-values less than 0.01 were considered statistically significant.

\section{Results}

Basic information of cases and controls

The basic information of cases and controls were listed in Table S2, including age, smoking status and so on. Statistically significant difference in the distributions of gender and age between the case group and the control group were found. And the basic information of five CYP4F2 polymorphisms was displayed in Table 1. The genotype distribution of SNPs among controls were in accordance with HWE $(p>0.05)$. The frequency distribution of allele A of rs3093203 was significantly different between cases and controls $(p=0.005)$, from which we found it to be associated with an increased risk of COPD $(\mathrm{OR}=1.40$, 95\%CI: 1.11-1.77) in the Hainan Han population. Also, rs3093193 $\mathrm{G}$ and rs3093110 $\mathrm{G}$ can reduce COPD risk $(p=0.003, p<0.000)$ in the Hainan Han population. The Regulome DB and HaploReg v4.1 were used to predict the SNPs function shown in Table S6.

\section{Genetic model analysis between CYP4F2 variants and COPD risk}

We further explored the relationship between CYP4F2 variants and COPD risk using four genetic models listed in Table 2. Individuals with rs3093203 AG-GG genotype had a much risk of COPD (OR $=1.49,95 \%$ CI: $1.11-1.99$, $p=0.008)$ compared to individuals with AA genotype in the dominant model. In the log-additive model, the results showed rs3093203 was correlated with the risk of COPD $(\mathrm{OR}=1.41,95 \% \mathrm{CI}: 1.11-1.79, p=0.004)$ without adjustment.

Additionally, patients with genotype CC of rs3093193 had a reduced risk of COPD in the codominant model (OR $=0.39$, 95\%CI: 0.19-0.77, $p=0.007)$ without adjustment. In the additive model, the SNP was associated with a reduced risk of COPD $(\mathrm{OR}=0.69$, 95\%CI: $0.54-$ $0.88, p=0.002$ ) c without adjustment for gender and age.

When compared to the GG genotype of rs3093110, heterozygous genotype GA was associated a decreased risk of COPD in the codominant model without adjustment for gender and age $(\mathrm{OR}=0.48,95 \% \mathrm{CI}$ : $0.32-0.72$, $p<0.000)$. Also, in the dominant model, genotype GAAA were linked with a reduced the risk of COPD than genotype GG without adjustment $(\mathrm{OR}=0.45$, 95\%CI: $0.30-0.67, p<0.000)$. The log-additive model showed there was significantly decreased association between rs3093110 and COPD risk without adjustment for gender and age $(\mathrm{OR}=0.44,95 \% \mathrm{CI}: 0.30-0.65, \mathrm{p}<0.000)$. After adjustment for gender and age, the variant was still related to the risk of COPD.

Table 1 Basic information and allele frequencies of the SNPs in CYP4F2

\begin{tabular}{|c|c|c|c|c|c|c|c|c|c|}
\hline \multirow[t]{2}{*}{ SNP } & \multirow[t]{2}{*}{ Chr } & \multirow[t]{2}{*}{ Gene } & \multirow{2}{*}{$\begin{array}{l}\text { Alleles } \\
A<B\end{array}$} & \multirow[t]{2}{*}{ Role } & \multicolumn{2}{|c|}{$\operatorname{MAF}(\mathrm{A})$} & \multirow{2}{*}{$\begin{array}{l}\text { HWE } \\
p \text {-value }\end{array}$} & \multirow[t]{2}{*}{ OR(95\%Cl) } & \multirow[t]{2}{*}{$p$-value } \\
\hline & & & & & Case & Control & & & \\
\hline rs3093203 & 19 & CYP4F2 & $A / G$ & $3^{\prime} U T R$ & 0.292 & 0.227 & 0.704 & $1.40(1.11-1.77)$ & 0.005 \\
\hline rs3093193 & 19 & CYPAF2 & $\mathrm{G} / \mathrm{C}$ & Intron & 0.219 & 0.286 & 0.664 & $0.70(0.55-0.88)$ & 0.003 \\
\hline rs12459936 & 19 & CYPAF2 & $\mathrm{T} / \mathrm{C}$ & Intron & 0.484 & 0.463 & 0.721 & $1.09(0.89-1.33)$ & 0.398 \\
\hline rs3093144 & 19 & CYPAF2 & $\mathrm{T} / \mathrm{C}$ & Intron & 0.139 & 0.164 & 0.517 & $0.82(0.62-1.09)$ & 0.167 \\
\hline rs3093110 & 19 & CYP4F2 & $\mathrm{G} / \mathrm{A}$ & Intron & 0.059 & 0.123 & 0.838 & $0.45(0.31-0.66)$ & $p<0.000$ \\
\hline
\end{tabular}

95\%Cl: 95\% confidence interval, HWE Hardy-Weinberg equilibrium, MAF minor allele frequency, OR odds ratio, SNP single-nucleotide polymorphism $p$-value: Calculated by Pearson $x^{2}$ test 
Table 2 Significant CYP4F2 variants associated with COPD susceptibility

\begin{tabular}{|c|c|c|c|c|c|c|c|c|}
\hline \multirow[t]{2}{*}{ SNP } & \multirow[t]{2}{*}{ Model } & \multirow[t]{2}{*}{ Genotype } & \multirow[t]{2}{*}{ Control } & \multirow[t]{2}{*}{ Case } & \multicolumn{2}{|l|}{ Unadjusted } & \multicolumn{2}{|c|}{ Adjusted for Gender and Age } \\
\hline & & & & & $\overline{\mathrm{OR}(95 \% \mathrm{Cl})}$ & $p^{\mathrm{a}}$-value & $\overline{\mathrm{OR}}(95 \% \mathrm{Cl})$ & $p^{\mathrm{b}}$-value \\
\hline \multirow[t]{8}{*}{ rs3093203 } & & AA & 24 & 22 & 1 & & 1 & \\
\hline & Codominant & $A G$ & 182 & 121 & $1.43(1.05-1.93)$ & 0.023 & $1.15(0.78-1.69)$ & 0.482 \\
\hline & & GG & 300 & 140 & $1.97(1.07-3.62)$ & 0.031 & $0.99(0.44-2.24)$ & 0.985 \\
\hline & Dominant & AA & 206 & 143 & 1 & & 1 & \\
\hline & & AG-GG & 300 & 140 & $1.49(1.11-1.99)$ & 0.008 & $1.13(0.78-1.63)$ & 0.526 \\
\hline & Recessive & $A A-A G$ & 24 & 22 & 1 & & 1 & \\
\hline & & GG & 482 & 261 & $1.69(0.93-3.08)$ & 0.084 & $0.94(0.42-2.07)$ & 0.869 \\
\hline & Log-additive & - & - & - & $1.41(1.11-1.79)$ & 0.004 & $1.07(0.80-1.46)$ & 0.646 \\
\hline \multirow[t]{8}{*}{ rs3093193 } & & GG & 39 & 11 & 1 & & 1 & \\
\hline & Codominant & GC & 212 & 115 & $0.74(0.55-1.00)$ & 0.048 & $0.93(0.65-1.34)$ & 0.704 \\
\hline & & $\mathrm{CC}$ & 256 & 187 & $0.39(0.19-0.77)$ & 0.007 & $0.49(0.21-1.14)$ & 0.099 \\
\hline & Dominant & GG & 251 & 126 & 1 & & 1 & \\
\hline & & GC-CC & 256 & 187 & $0.69(0.52-0.91)$ & 0.010 & $0.86(0.61-1.23)$ & 0.421 \\
\hline & Recessive & GG-GC & 39 & 11 & 1 & & 1 & \\
\hline & & $\mathrm{CC}$ & 468 & 302 & $0.44(0.22-0.87)$ & 0.018 & $0.51(0.22-1.16)$ & 0.108 \\
\hline & Log-additive & - & - & - & $0.69(0.54-0.88)$ & 0.002 & $0.82(0.61-1.11)$ & 0.197 \\
\hline \multirow[t]{8}{*}{ rs3093110 } & & GG & 8 & 0 & 1 & & 1 & \\
\hline & Codominant & GA & 109 & 37 & $0.48(0.32-0.72)$ & $p<0.000$ & $0.46(0.28-0.76)$ & 0.002 \\
\hline & & AA & 390 & 275 & - & - & - & - \\
\hline & Dominant & GG & 117 & 37 & 1 & & 1 & \\
\hline & & GA-AA & 390 & 275 & $0.45(0.30-0.67)$ & $p<0.000$ & $0.44(0.27-0.72)$ & 0.001 \\
\hline & Recessive & GG-GA & 8 & 0 & 1 & & 1 & \\
\hline & & $\mathrm{AA}$ & 499 & 312 & - & - & - & - \\
\hline & Log-additive & - & - & - & $0.44(0.30-0.65)$ & $p<0.000$ & $0.44(0.27-0.72)$ & 0.001 \\
\hline
\end{tabular}

95\%Cl: 95\% confidence interval, OR odds ratio, SNP single-nucleotide polymorphism $p^{\text {a }}$ : Calculated by logistic regression analysis $p^{\text {b }}$ : Calculated by logistic regression analysis adjusted for gender and age Bold type indicates statistical significance $(p<0.01)$

\section{Stratification analysis by gender}

We also used gender stratification to investigate the association between CYP4F2 SNPs and the risk of COPD (Table 3). Pearson's Chi-square test showed that the frequency distribution of minor allele of rs3093110 was significantly different between the male controls and the male patients $(p=0.000)$. There was a significant association between rs3093110 and COPD risk in the codominant $(\mathrm{OR}=0.45,95 \% \mathrm{CI}: 0.27-0.73, p=0.002)$, dominant $(\mathrm{OR}=0.42,95 \% \mathrm{CI}: 0.26-0.69, p=0.001)$ and log-additive $(\mathrm{OR}=0.42,95 \% \mathrm{CI}: 0.26-0.68, p<0.000)$ models. After adjusted for gender and age, the significant association still existed ( $p=0.005,0.004$ and 0.004). However, there was no significant relationship between $C Y P 4 F 2$ variants and COPD risk in females (Table S3).

\section{Stratification analysis by smoking status}

We also used smoking status stratification to investigate the correlation between candidate SNP and COPD risk listed in Table 4. We found that rs3093110 was significantly associated with an increased risk of COPD in the non-smoker group in the codominant $(\mathrm{OR}=0.42,95 \%$ CI: $0.23-0.78, p=0.006)$, dominant $(\mathrm{OR}=0.40,95 \% \mathrm{CI}$ : $0.22-0.74, p=0.004)$ and log-additive $(\mathrm{OR}=0.40,95 \%$ CI: $0.22-0.73, p=0.003)$ models. But, the significant association between rs3093110 and COPD risk was not found in the smokers.

\section{LD and haplotype analysis}

We also applied the Haploview software to do LD analysis in CYP4F2 variants (rs3093203, rs3093193, rs12459936, rs3093144 and rs3093110). A strong linkage mapped to a $18 \mathrm{~kb}$ LD block between rs3093203 and rs3093110 was found (Fig. 1). In addition, haplotypes GGCCG and GCCCA were associated with an increased risk of COPD $(\mathrm{OR}=2.15, \quad 95 \% \mathrm{CI}: \quad 1.46-3.16, \quad p<0.000 ; \quad \mathrm{OR}=16.22$, 95\%CI: 2.19-120.30, $p=0.006)$. Whereas, haplotypes GGCCA and ACCCA decreased the risk of COPD $(\mathrm{OR}=$ 
Table 3 Significant CYP4F2 variants associated with COPD susceptibility in males

\begin{tabular}{|c|c|c|c|c|c|c|c|c|}
\hline \multirow[t]{2}{*}{ SNP } & \multirow[t]{2}{*}{ Model } & \multirow[t]{2}{*}{ Genotype } & \multirow[t]{2}{*}{ Control } & \multirow[t]{2}{*}{ Case } & \multicolumn{2}{|l|}{ Unadjusted } & \multicolumn{2}{|c|}{ Adjusted for Gender and Age } \\
\hline & & & & & $\overline{\mathrm{OR}(95 \% \mathrm{Cl})}$ & $p^{\mathrm{a}}$-value & $\overline{\mathrm{OR}}(95 \% \mathrm{Cl})$ & $p^{\mathrm{b}}$-value \\
\hline \multirow[t]{8}{*}{ rs3093203 } & & AA & 17 & 18 & 1 & & 1 & \\
\hline & Codominant & $A G$ & 124 & 93 & $1.43(1.00-2.04)$ & 0.052 & $1.04(0.64-1.68)$ & 0.881 \\
\hline & & GG & 196 & 103 & $2.02(1.00-4.08)$ & 0.051 & $1.13(0.42-3.03)$ & 0.804 \\
\hline & Dominant & AA & 141 & 111 & 1 & & 1 & \\
\hline & & AG-GG & 196 & 103 & $1.50(1.06-2.11)$ & 0.022 & $1.05(0.66-1.66)$ & 0.838 \\
\hline & Recessive & $A A-A G$ & 17 & 18 & 1 & & 1 & \\
\hline & & GG & 320 & 196 & $1.73(0.87-3.43)$ & 0.118 & $1.12(0.43-2.92)$ & 0.825 \\
\hline & Log-additive & - & - & - & $1.42(1.08-1.88)$ & 0.013 & $1.05(0.72-1.53)$ & 0.799 \\
\hline \multirow[t]{8}{*}{ rs3093193 } & & GG & 18 & 6 & 1 & & 1 & \\
\hline & Codominant & GC & 141 & 88 & $0.77(0.54-1.08)$ & 0.133 & $1.08(0.68-1.70)$ & 0.756 \\
\hline & & $\mathrm{CC}$ & 177 & 144 & $0.41(0.16-1.06)$ & 0.066 & $0.61(0.18-2.09)$ & 0.435 \\
\hline & Dominant & GG & 159 & 94 & 1 & & 1 & \\
\hline & & GC-CC & 177 & 144 & $0.73(0.52-1.02)$ & 0.063 & $1.03(0.66-1.6)$ & 0.907 \\
\hline & Recessive & GG-GC & 18 & 6 & 1 & & 1 & \\
\hline & & $\mathrm{CC}$ & 318 & 232 & $0.46(0.18-1.17)$ & 0.102 & $0.60(0.18-1.99)$ & 0.399 \\
\hline & Log-additive & - & - & - & $0.72(0.54-0.97)$ & 0.030 & $0.96(0.65-1.42)$ & 0.852 \\
\hline \multirow[t]{8}{*}{ rs3093110 } & & GG & 4 & 0 & 1 & & 1 & \\
\hline & Codominant & GA & 67 & 24 & $0.45(0.27-0.73)$ & 0.002 & $0.39(0.20-0.76)$ & 0.005 \\
\hline & & AA & 265 & 213 & - & - & - & - \\
\hline & Dominant & GG & 71 & 24 & 1 & & 1 & \\
\hline & & GA-AA & 265 & 213 & $0.42(0.26-0.69)$ & 0.001 & $0.38(0.19-0.73)$ & 0.004 \\
\hline & Recessive & GG-GA & 4 & 0 & 1 & & 1 & \\
\hline & & $\mathrm{AA}$ & 332 & 237 & - & - & - & - \\
\hline & Log-additive & - & - & - & $0.42(0.26-0.68)$ & $p<0.000$ & $0.38(0.20-0.73)$ & 0.004 \\
\hline
\end{tabular}

95\%Cl: 95\% confidence interval, OR odds ratio, SNP single-nucleotide polymorphism $p^{a}$ : Calculated by logistic regression analysis $p^{\mathrm{b}}$ : Calculated by logistic regression analysis adjusted for gender and age Bold type indicates statistical significance $(p<0.01)$

0.14, 95\%CI: 0.04-0.49, $p=0.002$; OR $=0.68,95 \%$ CI: $0.54-$ $0.86, p=0.001)$. The relationship between haplotypes GGCTA, GCTCA and the risk of COPD were still not found (Table 5). After gender stratification, significant association between haplotypes GGCCG, ACCCA and the risk of COPD in males shown in Table S4. And when stratified analysis by smoking status (Table S5), haplotype GGCT showed the association with an increased risk of COPD (adjusted OR $=1.95,95 \%$ CI: $1.02-3.73, p=0.042$ ) in the smokers, while haplotype ACCC significantly associated with the risk of COPD in non-smokers $(\mathrm{OR}=1.59$, 95\%CI: 1.14-2.21, $\mathrm{p}=0.006)$.

\section{Discussion}

In this study, we explored the connections of five variants of CYP4F2 and COPD risk in a Chinese Han population. Our results showed that rs3093203, rs3093193 and rs3093110 were significantly associated with the risk of COPD. After gender stratification, males with CYP4F2 variants (rs3093203, rs3093193 and rs3093110) showed the association with COPD risk. And the results of smoking status stratification showed that rs3093144 was associated with an increased risk of COPD in the smoker group. So, we speculated that CYP4F2 variants may be involved in the pathogenesis of COPD.

CYP4F2, located in the chromosome 19p13.12, contains 12 introns and 13 exons, which is a part of CYP4F gene cluster. Transgenic mice experiment by Lai et al. demonstrated that CYP4F2 was only expressed in the liver [24]. In the investigation of the effect of genetic variability in the CYP4F gene cluster on expression of the individual CYP4F genes in the liver, the results showed that CYP4F2 rs2108622 was correlated with an increased CYP4F2 mRNA expression level [25]. In addition, rs2108622 G was associated with IS in the Japanese men [21]. Another article reported by Liao et al. illustrated that CYP4F2 genetic variants were significantly correlated with IS risk and 20- 
Table 4 Relationship of CYP4F2 gene polymorphisms and risk of COPD stratified by Smoking status

\begin{tabular}{|c|c|c|c|c|c|c|c|c|c|c|}
\hline \multirow[t]{2}{*}{ SNP } & \multirow[t]{2}{*}{ Model } & \multirow[t]{2}{*}{ Genotype } & \multicolumn{4}{|c|}{ Smoking } & \multicolumn{4}{|c|}{ Non-smoking } \\
\hline & & & Control & Case & $\mathrm{OR}(95 \% \mathrm{Cl})$ & $p$-value & Control & Case & $\mathrm{OR}(95 \% \mathrm{Cl})$ & $p$-value \\
\hline \multirow[t]{8}{*}{ rs3093203 } & & AA & 14 & 12 & 1 & & 10 & 9 & 1 & \\
\hline & Codominant & $A G$ & 80 & 54 & $1.01(0.52-1.96)$ & 0.977 & 102 & 66 & $1.32(0.80-2.16)$ & 0.277 \\
\hline & & GG & 121 & 67 & $0.81(0.22-3.02)$ & 0.758 & 179 & 73 & $1.08(0.34-3.38)$ & 0.899 \\
\hline & Dominant & AA & 14 & 12 & 1 & & 10 & 9 & 1 & \\
\hline & & AG-GG & 201 & 121 & $0.98(0.52-1.85)$ & 0.949 & 281 & 139 & $1.29(0.80-2.08)$ & 0.301 \\
\hline & Recessive & AA-AG & 94 & 66 & 1 & & 112 & 75 & 1 & \\
\hline & & GG & 121 & 67 & $0.81(0.23-2.91)$ & 0.747 & 179 & 73 & $0.96(0.31-2.94)$ & 0.938 \\
\hline & Log-additive & - & - & - & $0.95(0.57-1.59)$ & 0.855 & - & - & $1.19(0.8-1.79)$ & 0.396 \\
\hline \multirow[t]{8}{*}{ rs3093193 } & & GG & 16 & 4 & 1 & & 23 & 7 & 1 & \\
\hline & Codominant & GC & 89 & 56 & $1.41(0.74-2.72)$ & 0.298 & 123 & 58 & $0.78(0.49-1.25)$ & 0.306 \\
\hline & & CC & 110 & 87 & $2.07(0.44-9.59)$ & 0.355 & 146 & 99 & $0.36(0.13-1.02)$ & 0.054 \\
\hline & Dominant & GG & 16 & 4 & 1 & & 23 & 7 & 1 & \\
\hline & & GC-CC & 199 & 143 & $1.46(0.77-2.76)$ & 0.241 & 269 & 157 & $0.71(0.45-1.11)$ & 0.134 \\
\hline & Recessive & GG-GC & 105 & 60 & 1 & & 146 & 65 & 1 & \\
\hline & & CC & 110 & 87 & $1.76(0.39-7.90)$ & 0.458 & 146 & 99 & $0.40(0.15-1.11)$ & 0.078 \\
\hline & Log-additive & - & - & - & $1.42(0.83-2.45)$ & 0.204 & - & - & $0.69(0.48-1.01)$ & 0.054 \\
\hline \multirow[t]{8}{*}{ rs3093110 } & & GG & 4 & 0 & 1 & & 4 & 0 & 1 & \\
\hline & Codominant & GA & 41 & 16 & $0.61(0.24-1.51)$ & 0.282 & 68 & 21 & $0.42(0.23-0.78)$ & 0.006 \\
\hline & & AA & 171 & 131 & - & - & 219 & 142 & - & - \\
\hline & Dominant & GG & 4 & 0 & 1 & & 4 & 0 & 1 & \\
\hline & & GA-AA & 212 & 147 & $0.58(0.24-1.43)$ & 0.237 & 287 & 163 & $0.40(0.22-0.74)$ & 0.004 \\
\hline & Recessive & GG-GA & 45 & 16 & 1 & & 72 & 21 & 1 & \\
\hline & & AA & 171 & 131 & - & - & 219 & 142 & - & - \\
\hline & Log-additive & - & - & - & $0.57(0.24-1.37)$ & 0.211 & - & - & $0.40(0.22-0.73)$ & 0.003 \\
\hline
\end{tabular}

95\%Cl: 95\% confidence interval, OR odds ratio, SNP single-nucleotide polymorphism $p$-value: Calculated by logistic regression analysis adjusted for gender and age Bold type indicates statistical significance $(p<0.01)$

Hydroxyeicosatetraenoic Acid Level (20-HETE) [20]. IS patients with the genotype combination of rs9333025 GG and rs2108622 GG had higher 20-HETE levels compared to IS patients with other combinations of the two variants, which demonstrated that the interaction between rs9333025 GG and rs2108622 GG can increase capability to metabolize arachidonic acid to produce 20HETE. The evaluated 20-HETE levels were related to vascular oxidative stress, endothelial dysfunction and high peripheral vascular resistance [26, 27]. And Parker found that pharmacological inhibition of 20-HETE can abolish the myogenic response during NOS antagonism in the ovine fetal pulmonary circulation [28]. Overall, 20-HETE, a biologically active 20-carbohydrate and therapeutic intervention target, involved in a variety of vascular events, such as regulating blood pressure, renal function, cerebral blood flow and pulmonary circulation $[26,27]$. So, we speculated that the polymorphisms of
CYP4F2 gene affected the pathogenesis of disease by altering arachidonic acid metabolism to produce 20HETE.

In the year of 2011, the expression of CYP4F2 was found by Falus et al. to be a rapid elevation when children with respiratory disease to polarized light therapy [29]. In 2018, rs2074900 in CYP4F2 was found to be significantly related to therapeutic responses to erlotinib in sixty Han Chinese advanced non-small cell lung cancer patients received erlotinib monotherapy [16]. The above results indicated that CYP4F2 was involved in the pathogenesis of pulmonary disease and CYP4F2 variants played a vital role in the lung disease. In our results, we did not find a link between this site and the risk of COPD, but we firstly revealed that CYP4F2 variants (rs3093203, rs3093193 and rs3093110) were associated with the risk of COPD. In future, we will increase the sample size and continue to study the results, and 


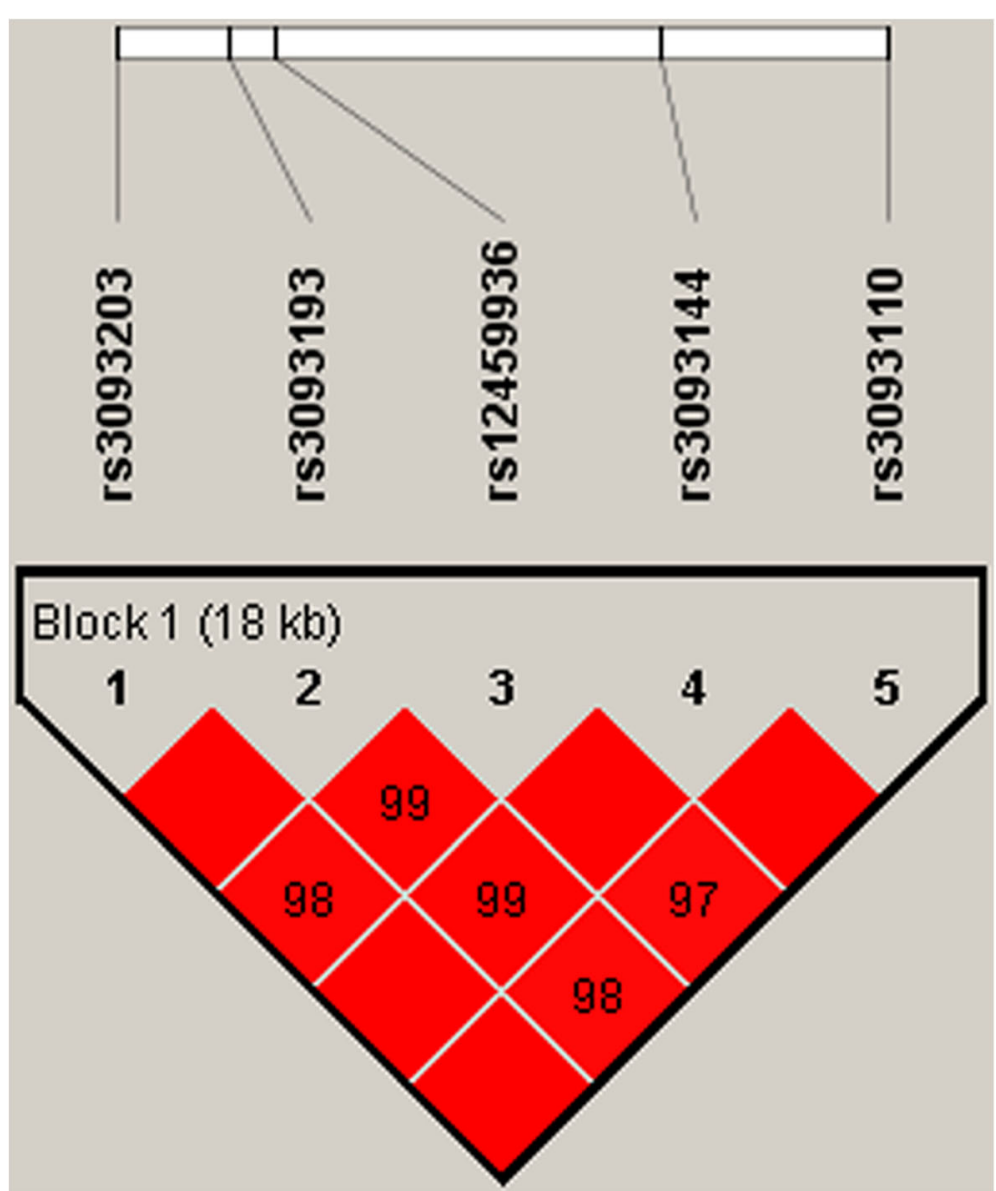

Fig. 1 Linkage disequilibrium (LD) analysis of five SNPs in CYP4F2. The LD value is determined by $r^{2}>0.8$ analyzed by Haploview software 4.2 . The number in the diamonds is the LOD score of $r^{2}$. Standard color schemes indicate the different levels of LD. Bright red: $L O D>2, D^{\prime}=1$

Table 5 CYP4F2 haplotypes frequencies associated with COPD risk

\begin{tabular}{|c|c|c|c|c|c|c|c|c|}
\hline \multirow[t]{2}{*}{ Gene } & \multirow[t]{2}{*}{ SNP } & \multirow[t]{2}{*}{ Haplotype } & \multicolumn{2}{|c|}{ Frequency } & \multicolumn{2}{|l|}{ Unadjusted } & \multicolumn{2}{|c|}{$\begin{array}{l}\text { Adjusted for Gender and } \\
\text { Age }\end{array}$} \\
\hline & & & Case & Control & OR $(95 \% \mathrm{Cl})$ & $p^{\text {a-value }}$ & $\mathrm{OR}(95 \% \mathrm{Cl})$ & $\begin{array}{l}p^{b}- \\
\text { value }\end{array}$ \\
\hline CYP4F2 & rs3093203|rs3093193|rs12459936|rs3093144|rs3093110 & GGCCG & 0.941 & 0.881 & $2.15(1.46-3.16)$ & $\begin{array}{l}p< \\
0.000\end{array}$ & $2.21(1.36-3.60)$ & 0.001 \\
\hline CYP4F2 & rs3093203|rs3093193|rs12459936|rs3093144|rs3093110 & GGCTA & 0.139 & 0.162 & $0.83(0.62-1.11)$ & 0.201 & $1.02(0.72-1.46)$ & 0.896 \\
\hline CYP4F2 & rs3093203|rs3093193|rs12459936|rs3093144|rs3093110 & GCTCA & 0.486 & 0.461 & $1.11(0.91-1.36)$ & 0.317 & $1.21(0.94-1.55)$ & 0.150 \\
\hline CYP4F2 & rs3093203|rs3093193|rs12459936|rs3093144|rs3093110 & GGCCA & 0.979 & 0.997 & $0.14(0.04-0.49)$ & 0.002 & $0.09(0.02-0.41)$ & 0.002 \\
\hline CYP4F2 & rs3093203|rs3093193|rs12459936|rs3093144|rs3093110 & ACCCA & 0.706 & 0.776 & $0.68(0.54-0.86)$ & 0.001 & $0.91(0.68-1.23)$ & 0.536 \\
\hline CYP4F2 & rs3093203|rs3093193|rs12459936|rs3093144|rs3093110 & GCCCA & 0.998 & 0.975 & $\begin{array}{l}16.22(2.19- \\
120.30)\end{array}$ & 0.006 & $\begin{array}{l}15.18(1.65- \\
139.60)\end{array}$ & 0.016 \\
\hline
\end{tabular}

95\%Cl: 95\%Confidence interval, OR Odds ratio, SNP Single nucleotide polymorphism

$p^{a}$ values were calculated by logistic regression analysis without adjusted

$p^{\mathrm{b}}$ values were calculated by logistic regression analysis after adjusted for gender and age 
continue to explore the polymorphisms of CYP4F2 gene to affect the pathogenesis of COPD by changing the yield of 20-HETE.

\section{Conclusions}

In conclusion, we revealed that rs3093203, rs3093193 and rs3093110 were significantly associated with the risk of COPD, especially in the Hainan male population. Rs3093144 may be a risk factor shown from the smoking status. The overall results may provide more evidences for COPD risk diagnosis.

\section{Supplementary information}

Supplementary information accompanies this paper at https://doi.org/10. 1186/s12931-020-01348-6.

\section{Additional file 1: Table S1. PCR primers for amplification and}

extension of loci used in this study.

Additional file 2: Table S2. The basic information of cases and controls.

Additional file 3: Table S3. Significant CYP4F2 variants associated with COPD susceptibility in females.

Additional file 4 Table S4. CYP4F2 haplotypes frequencies associated with COPD risk in males.

Additional file 5: Table S5. CYP4F2 haplotypes frequencies associated with COPD risk in smokers and non-smokers.

Additional file 6: Table S6. In silico analysis for SNPs function annotation.

\section{Acknowledgments}

We are very grateful to those who participated in this manuscript. Meanwhile, we also thank a professional person for the valuable suggestions to the work.

\section{Authors' contributions}

Yipeng Ding, Yixiu Yang, Quanni Li, Oiong Feng and Jianfang Liu completed genotyping and performed the manuscript. Dongchuan Xu, Cibing Wu, Jie Zhao, Xiaoli Zhou, Huan Niu and Ping He participated in the data management, statistical analysis and modified the manuscript. Yipeng Ding and Hongxia Yao designed the study, co-supervised the work and modified the manuscript. All authors have approved the final manuscript.

\section{Funding}

This work was supported by the National Natural Science Foundation of China (No. 81660013 and No.81860015) and Key Research and Development Plan of Hainan province (No. ZDYF2018116).

\section{Availability of data and materials}

Not applicable.

\section{Ethics approval and consent to participate}

The study was approved by the Ethics Committee of Hainan General Hospital (Med-Eth-Re [2019]42) and we obtained written informed consent from all individual participants.

\section{Consent for publication}

Not applicable.

\section{Competing interests}

The authors declare that they have no competing interests.

\section{Author details}

'Department of General Practice, Hainan General Hospital, Haikou 570102 Hainan, China. ${ }^{2}$ Hainan Affiliated Hospital of Hainan Medical University, \#19,
Xiuhua Road, Xiuying District, Haikou 570102, Hainan, China. ${ }^{3}$ Hainan General Hospital, University of South China, Haikou 570102, Hainan, China.

Received: 6 November 2019 Accepted: 1 April 2020

Published online: 15 April 2020

\section{References}

1. Vos T, Allen C, Arora M, Barber RM, Bhutta ZA, Brown A, Carter A, Casey DC, Charlson FJ, Chen AZ. Global, regional, and national incidence, prevalence, and years lived with disability for 310 diseases and injuries, 1990-2015: a systematic analysis for the global burden of disease study 2015. Lancet. 2016;388:1545-602.

2. Adeloye D, Chua S, Lee C, Basquill C, Papana A, Theodoratou E, Nair H, Gasevic D, Sridhar D, Campbell H. Global and regional estimates of COPD prevalence: systematic review and meta-analysis. J Glob Health. 2015;5: 020415.

3. Murphy SL, Xu J, Kochanek KD, Arias E. Mortality in the United States, 2017. NCHS Data Brief. 2018:1-8.

4. Wheaton AG, Cunningham TJ, Ford ES, Croft JB. Employment and activity limitations among adults with chronic obstructive pulmonary disease United States, 2013. Morb Mortal Wkly Rep. 2015;64:289-95

5. Ford ES, Mannino DM, Wheaton AG, Giles WH, Presley-Cantrell L, Croft JB. Trends in the prevalence of obstructive and restrictive lung function among adults in the United States: findings from the National Health and nutrition examination surveys from 1988-1994 to 2007-2010. Chest. 2013;143:1395-406.

6. Singh D, Agusti A, Anzueto A, Barnes PJ, Bourbeau J, Celli BR. Global Strategy for the Diagnosis, Management, and Prevention of Chronic Obstructive Lung Disease: the GOLD science committee report 2019. Eur Respir J. 2019;53.

7. Zhou M, Wang H, Zhu J, Chen W, Wang L, Liu S, Li Y, Wang L, Liu Y, Yin P. Cause-specific mortality for 240 causes in China during 1990-2013: a systematic subnational analysis for the global burden of disease study 2013. Lancet. 2016;387:251-72.

8. Zhong N, Wang C, Yao W, Chen P, Kang J, Huang S, Chen B, Wang C, Ni D, Zhou Y. Prevalence of chronic obstructive pulmonary disease in China a large, population-based survey. Am J Respir Crit Care Med. 2007:176:753-60.

9. $\quad$ Bi $Y$, Jiang $Y$, He J, Xu Y, Wang L, Xu M, Zhang M, Li Y, Wang T, Dai M. Status of cardiovascular health in Chinese adults. J Am Coll Cardiol. 2015;65: 1013-25.

10. Wang B, Zhou H, Yang J, Xiao J, Liang B, Li D, Zhou H, Zeng Q, Fang C, Rao Z. Association of HHIP polymorphisms with COPD and COPD-related phenotypes in a Chinese Han population. Gene. 2013;531:101-5.

11. Kim WJ, Lee MK, Shin C, Cho NH, Lee SD, Oh YM, Sung J. Genome-wide association studies identify locus on 6p21 influencing lung function in the Korean population. Respirology. 2014;19:360-8.

12. Uslu A, Ogus C, Ozdemir T, Bilgen T, Tosun O, Keser I. The effect of CYP1A2 gene polymorphisms on theophylline metabolism and chronic obstructive pulmonary disease in Turkish patients. J Biochem Mol Biol. 2010;43:530-4.

13. Sakornsakolpat P, Prokopenko D, Lamontagne M, Reeve NF, Guyatt AL, Jackson VE, Van Ginneken B, Young R, Zeiglerheitbrock L. Genetic landscape of chronic obstructive pulmonary disease identifies heterogeneous cell-type and phenotype associations. Nat Genet. 2019;51:494-505.

14. Zhu L, He Y, Niu F, Yan M, Li J, Yuan D, Jin T. Polymorphisms of drugmetabolizing enzyme CYP2E1 in Chinese Uygur population. Medicine (Baltimore). 2018;97:e9970.

15. Cao $P$, Zhao Q, Shao $Y$, Yang H, Jin T, Li B, Li H. Genetic polymorphisms of the drug-metabolizing enzyme CYP2J2 in a Tibetan population. Medicine (Baltimore). 2018;97:e12579.

16. Wang C, Chen F, Liu Y, Xu Q, Guo L, Zhang X, Ruan Y, Shi Y, Shen L, Li M, et al. Genetic Association of Drug Response to Erlotinib in Chinese advanced non-small cell lung Cancer patients. Front Pharmacol. 2018;9:360.

17. Van Engen CE, Ofman R, Dijkstra IME, Van Goethem TJ, Verheij E, Varin J, Vidaud M, Wanders RJA, Aubourg P, Kemp S. CYP4F2 affects phenotypic outcome in adrenoleukodystrophy by modulating the clearance of very long-chain fatty acids. Biochim Biophys Acta. 1862;2016:1861-70.

18. Wang H, Qiu T, Shi J, Liang J, Wang Y, Quan L, Zhang Y, Zhang Q, Tao K. Gene expression profiling analysis contributes to understanding the association between non-syndromic cleft lip and palate, and cancer. Mol Med Rep. 2016;13:2110-6.

19. Meng C, Wang J, Ge W, Tang S, Xu G. Correlation between CYP4F2 gene rs2108622 polymorphism and susceptibility to ischemic stroke. Int J Clin Exp Med. 2015;8:16122-6. 
20. Liao D, Yi X, Zhang B, Zhou Q, Lin J. Interaction between CYP4F2 rs2108622 and CPY4A11 rs9333025 variants is significantly correlated with susceptibility to ischemic stroke and 20-Hydroxyeicosatetraenoic acid level. Genet Test Mol Biomarkers. 2016:20:223-8.

21. Fu Z, Nakayama T, Sato N, Izumi Y, Kasamaki Y, Shindo A, Ohta M, Soma M, Aoi N, Sato M. A haplotype of the CYP4F2 gene is associated with cerebral infarction in Japanese men. Am J Hypertens. 2008;21:1216-23.

22. Vogelmeier C, Criner GJ, Martinez FJ, Anzueto A, Barnes PJ, Bourbeau J, Celli BR, Chen R, Decramer M, Fabbri L. Global Strategy for the Diagnosis, Management, and Prevention of Chronic Obstructive Lung Disease 2017 Report. GOLD Executive Summary. Am J Respir Critical Care Med. 2017;195: 557-82.

23. Ding Y, Yang D, Zhou L, Xu J, Chen Y, He P, Yao J, Chen J, Niu H, Sun P. Variants in multiple genes polymorphism association analysis of COPD in the Chinese Li population. Int J Chron Obstruct Pulmon Dis. 2015;10:1455-63.

24. Lai G, Liu X, Wu J, Liu H, Zhao Y. Evaluation of CMV and KAP promoters for driving the expression of human CYP4F2 in transgenic mice. Int J Mol Med. 2011;29:107-12.

25. Zhang JE, Klein K, Jorgensen AL, Francis B, Alfirevic A, Bourgeois S, Deloukas $P$, Zanger UM, Pirmohamed M. Effect of genetic variability in the CYP4F2, CYP4F11, and CYP4F12 genes on liver mRNA levels and warfarin response. Front Pharmacol. 2017:8:323.

26. Waldman M, Peterson SJ, Arad M, Hochhauser E. The role of 20-HETE in cardiovascular diseases and its risk factors. Prostaglandins Other Lipid Mediat. 2016;125:108-17.

27. Hoopes SL, Garcia V, Edin ML, Schwartzman ML, Zeldin DC. Vascular actions of 20-HETE. Prostaglandins Other Lipid Mediat. 2015;120:9-16.

28. Parker TA, Grover TR, Kinsella JP, Falck JR, Abman SH. Inhibition of 20-HETE abolishes the myogenic response during NOS antagonism in the ovine fetal pulmonary circulation. Am J Physiol Lung Cell Mol Physiol. 2005;289:L261-7.

29. Falus A, Fenyő M, Eder K, Madarasi A. Genome-wide gene expression study indicates the anti-inflammatory effect of polarized light in recurrent childhood respiratory disease. Inflamm Res. 2011;60:965-72.

\section{Publisher's Note}

Springer Nature remains neutral with regard to jurisdictional claims in published maps and institutional affiliations.

Ready to submit your research? Choose BMC and benefit from:

- fast, convenient online submission

- thorough peer review by experienced researchers in your field

- rapid publication on acceptance

- support for research data, including large and complex data types

- gold Open Access which fosters wider collaboration and increased citations

- maximum visibility for your research: over $100 \mathrm{M}$ website views per year

At $\mathrm{BMC}$, research is always in progress.

Learn more biomedcentral.com/submissions 